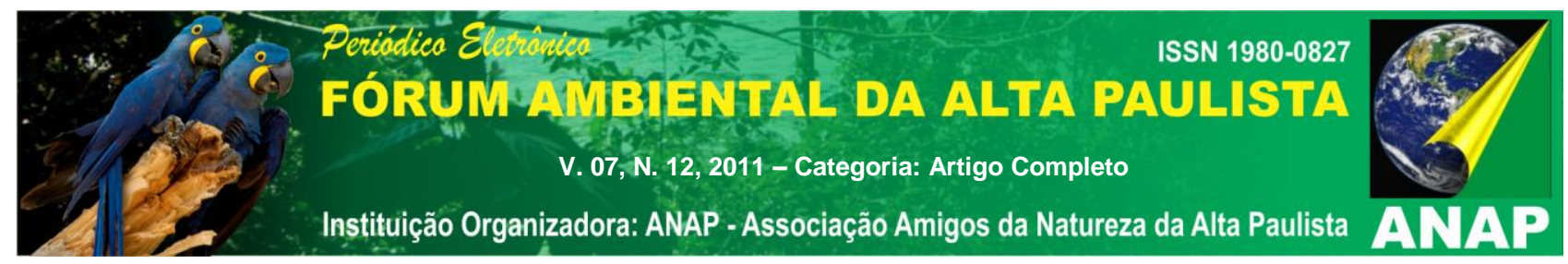

\title{
INFLUÊNCIA DA SAZONALIDADE CLIMÁTICA NA OCORRÊNCIA DE MOSCAS NO LIXÃO URBANO DE PRESIDENTE PRUDENTE, SÃO PAULO
}

\author{
Leonice Seolin Dias ${ }^{1}$ \\ Natacha Cíntia Regina Aleixo²
}

Raul Borges Guimarães ${ }^{3}$

RESUMO: As condições climáticas possibilitam o desenvolvimento de vetores, que podem proliferar de forma diferenciada de acordo com as estações do ano. Neste contexto, o objetivo deste trabalho é analisar a influência da sazonalidade nas famílias de moscas Calliphoridae e Muscidae no lixão urbano de Presidente Prudente, SP. Para captura dos insetos foram utilizadas seis armadilhas confeccionadas com garrafas "pet" contendo fígado bovino como atrativo. No total 26.508 moscas foram coletadas, sendo $87,48 \%$ (23.189) da família califorídeos e 12,52\% (3.319) muscídeos. A família mais abundante e constante nos três anos de estudo, em cada estação, foi a Calliphoridae. As duas famílias apresentaram frequências semelhantes, com maior abundancia na estação do verão e capturas reduzidas ou ausentes no inverno, dos três anos de estudo.

Palavras-chave: Geografia da Saúde, Clima, Vetores

\section{INTRODUÇÃO}

\footnotetext{
${ }_{1}^{1}$ Colaboradora do Laboratório Geografia da Saúde da UNESP, Presidente Prudente-SP (nseolin@gmail.com).

2 Doutoranda em Geografia da UNESP, Presidente Prudente-SP (natachaaleixo@yahoo.com.br).

${ }^{3}$ Professor assistente - Doutor do Departamento de Geografia da UNESP, Presidente Prudente-SP (raul@fct.unesp.br)
} 


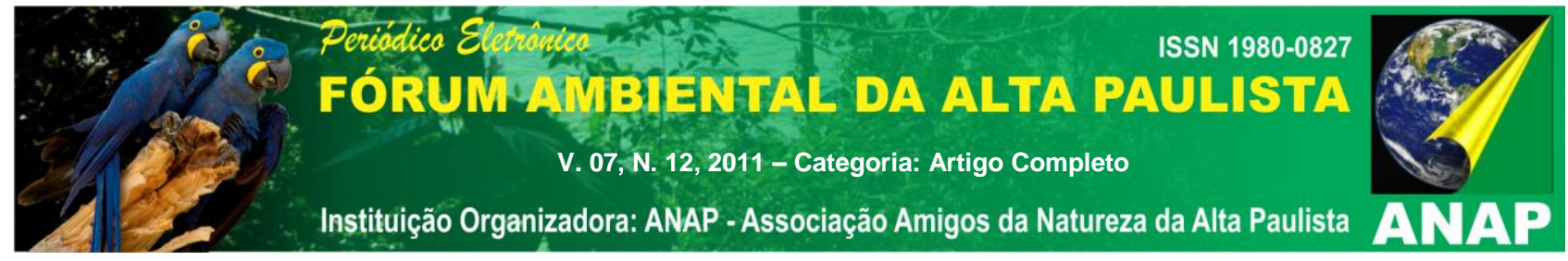

O município de Presidente Prudente está localizado em uma área de transição climática, conforme o estudo de Monteiro (1973), que classificou a atuação dos sistemas climáticos em todas as regiões do estado de São Paulo.

A transição zonal ocorre pela atuação de sistemas equatoriais e tropicais durante o verão e sistemas polares no inverno, com ondas de aquecimento pré-frontal pela atuação de massas frias de trajetória continental.

A atuação de sistemas tropicais e extra-tropicais faz com que o município apresente variabilidade climática acentuada, com regimes pluviométricos diferenciados nas estações do ano, além disso, possibilita a elevação da amplitude térmica conforme a atuação dos diferentes sistemas atmosféricos.

Segundo Amorim et al. (2009, p.11), os sistemas tropicais prevalecem na região a maior parte do ano, ora com o seu ramo atlântico, mais úmido, ora com trajetórias continentais, mais quentes e secas. Além disso, a atuação da Massa Tropical Atlântica Continentalizada (mTac) caracteriza-se por ser uma fácies da Ta devido às modificações que esta sofre ao avançar pelo continente. Como resultado tem-se temperatura mais elevada, umidade relativa baixa e pressões em ligeiro declínio (BARRIOS; SANT'ANNA NETO, 1996).

Durante o período de 1967 a 1996, Boin (2000), verificou a atuação dos trajetos principais das massas de ar que atuam no Oeste paulista e a intensidade de atuação das mesmas. Assim, o autor conseguiu sistematizar a Figura 1. 



Figura 1. Modelo dos Trajetos preferenciais das massas de ar que atingem o oeste paulista, em anos de pluviosidade habitual, as espessuras referem-se a intensidade de atuação. Fonte: Boin ( 2000).

Os elementos climáticos de Presidente Prudente foram mensurados na estação meteorológica da FCT/UNESP, e verificou-se que a cidade apresenta uma temperatura média anual de $23,2^{\circ} \mathrm{C}$ determinada pela continentalidade implícita à região. Os valores mensais oscilam num ciclo sazonal dividido em duas estações bem definidas: a primeira (de outubro a março) com temperaturas em torno de $25^{\circ} \mathrm{C}$ e, a segunda (menos quente) com temperaturas em torno de $20^{\circ} \mathrm{C}$. (BOLETIM CLIMATOLÓGICO, 1999)

Amorim et al. (2009, p.11) analisou o período de 1969-2007, e verificou que na primavera e verão, as temperaturas diárias oscilam entre os $20^{\circ} \mathrm{C}$ e $32^{\circ} \mathrm{C}$, com máximas absolutas próximas aos $40^{\circ} \mathrm{C}$. Nesta época do ano concentra-se cerca de $75 \%$ da precipitação anual de $1.300 \mathrm{~mm}$. No outono/inverno as temperaturas decrescem ligeiramente, mas permanecem elevadas, à exceção dos episódios das invasões do 


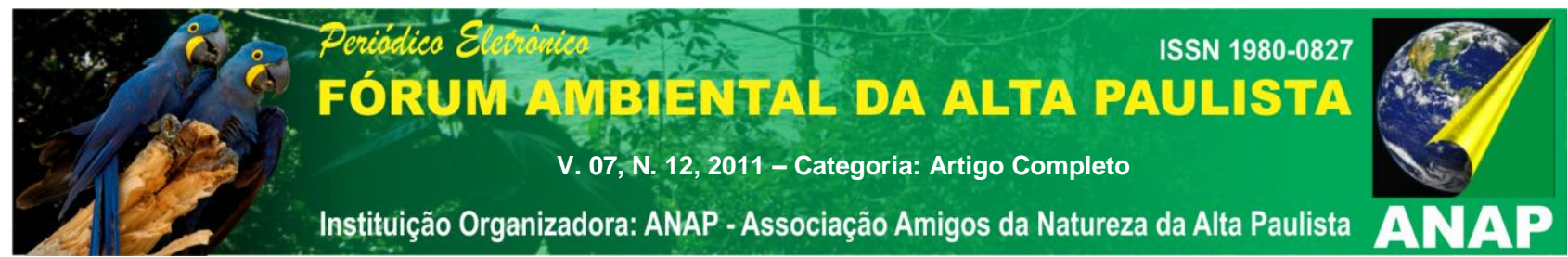

anticiclone polar, quando as temperaturas mínimas oscilam entre $15^{\circ} \mathrm{C}$ e $20^{\circ} \mathrm{C}$, com valores absolutos que podem chegar a $0^{\circ} \mathrm{C}$ característica de duas estações bem definidas: verão com altas temperaturas e elevada precipitação pluvial de outubro a março e inverno seco e ameno de abril a setembro.

A expansão urbana de Presidente Prudente, ao longo das décadas, impactou nos fluxos de matéria e energia advindos das globais e regionais. A partir disso, alguns estudos evidenciaram ilhas de calor na cidade, detectadas por diferentes metodologias.

O estudo de Amorim (2000) realizou medidas horárias da temperatura e umidade do ar entre as $7 \mathrm{~h}$ e $18 \mathrm{~h}$, e verificou que

As características da temperatura e da umidade relativa demonstraram que Presidente Prudente possui diferenças intraurbana e rural que permitem afirma que existe um clima urbano específico, fruto da combinação do tipo de uso e ocupação do solo, com a presença ou carência de vegetação, altitude e exposição de vertentes. A associação destes fatores permitiu compreender as anomalias da temperatura e da umidade relativa encontradas na pesquisa de campo em dois meses das estações extremas: janeiro (verão) e julho (inverno). Os tipos de tempo foram responsáveis pelas maiores ou menores magnitudes dos fenômenos conhecidos como ilha de calor e ilhas de frescor, assim como as ilhas secas e úmidas (AMORIM, 2002, p.191).

Em outro estudo sobre as características climáticas intra-urbanas de Presidente Prudente, com a utilização de transectos móveis no período diurno, Araújo et al. (2010) verificou que a temperatura do ar é aumenta à medida que o transecto adentra as áreas mais densamente construídas, e vice-versa à medida que o transecto se move para os limites da cidade, dando forma a ilha de calor urbana.

Nesta perspectiva, sabe-se que muitas doenças que acometem os seres humanos, são influenciadas de forma direta ou indireta pelas condições do tempo e do clima, por isso, são importantes: a análise da variabilidade e do ritmo climático de Presidente Prudente, sobre o processo saúde-doença que acomete a população.

Além disso, os fatores climáticos atuam sobre o sistema de vida dos insetos, isto é, estes influenciam diretamente em sua sobrevivência e proliferação.

Para Forattini (1962): 


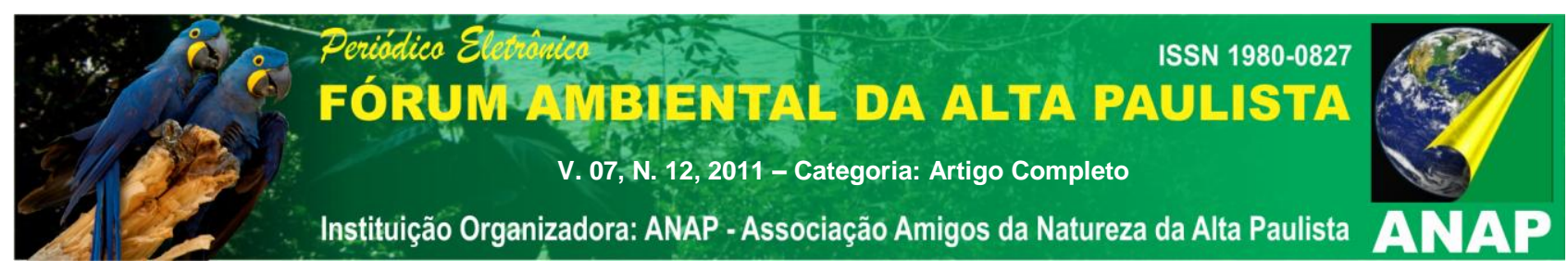

...os fatores climáticos principais, como a temperatura e a umidade, influem poderosamente sobre a composição das comunidades animais. Nas regiões tropicais, eles são pouco variáveis. O contrário acontece em outras, onde as estações do ano são bem marcadas. Assim sendo, o estudo das populações deve levar em consideração a variação estacional subordinada à variabilidade desses fatores climáticos. No nosso meio, por exemplo, as observações realizadas com diferentes espécies de insetos demonstram, de maneira evidente, a maior produção nos meses quentes e úmidos, em contra-posição à menor que ocorre nos meses frios e secos.

Por isso, é interessante compreender a flutuação populacional das espécies vetoras de enfermidades, uma vez que a variação populacional permite determinar os períodos e as condições de maior e menor transmissão.

As variações de temperatura e outros fatores climáticos influenciam diretamente sobre o tempo de duração do ciclo e no tamanho das populações da mosca doméstica, segundo Torres et al. (2002). E, conforme Minkin e Scott (1960), a distribuição de suas larvas nos materiais de procriação, em condições naturais, depende principalmente da temperatura e umidade.

Ressaltamos que a temperatura é um dos principais fatores abióticos que influenciam na reprodução e sobrevivência destas moscas, uma vez que ovos, larvas e adultos possuem seu desenvolvimento influenciado pela temperatura do ar, enquanto que as pupas pela temperatura do solo.

Ainda com relação à temperatura, Rodrigues (2004), ressalta que este fator abiótico é regulador da temperatura do inseto, já que este não possui um sistema de termo regulação (pecilotérmicos).

Desta forma, as moscas adultas desenvolvem-se bem na faixa de temperaturas entre $10^{\circ} \mathrm{C}$ e $15^{\circ} \mathrm{C}$, porém, as temperaturas inferiores reduzem consideravelmente sua vida. Permanecem inativas a temperaturas inferiores a $7,2^{\circ} \mathrm{C}$ morrendo em temperaturas inferiores a $0^{\circ} \mathrm{C}$. A máxima atividade desses dípteros é alcançada a $32^{\circ} \mathrm{C}$. (DAKSHINAMURT, 1948; SILVERLY, 1958; THORSTEINSON, 1958).

Nas áreas tropicais, a umidade do ar é influenciada amplamente pela precipitação pluvial, segundo Lara 1977, apresenta ação direta e, indireta, por meio da umidade do ar e do solo, pela evaporação e disponibilidade de água. 


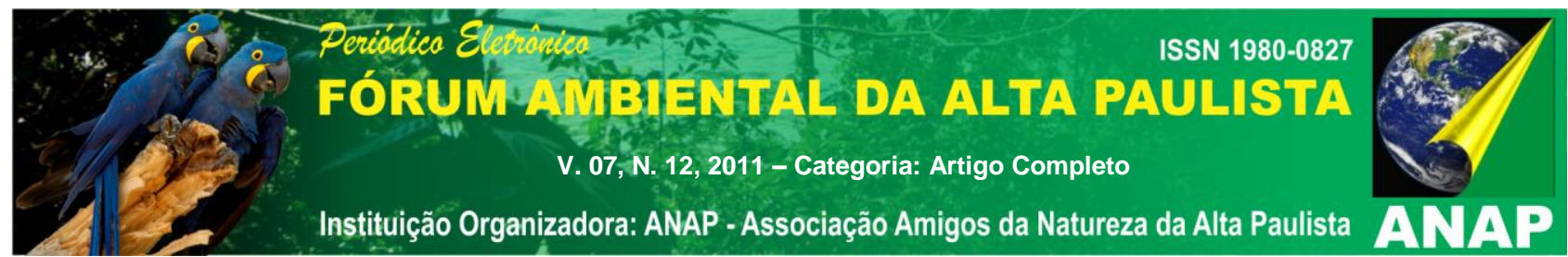

Neste contexto, Steve (1959) e Rodrigues (2011), relatam que a variação da umidade relativa esta diretamente ligada à variação da temperatura, de forma que os efeitos mortais das temperaturas tanto elevadas, como baixas, se acentuam mais quando a umidade é alta. A mais de $15^{\circ} \mathrm{C}$, as moscas sobrevivem por mais tempo quando a umidade relativa está entre 42 a 55\%. Algumas espécies de moscas alcançam um estado fisiológico ótimo a altas temperaturas e baixas umidades.

Diante de tais informações, o presente estudo tem como objetivo analisar a influência da sazonalidade nas famílias de moscas Calliphoridae e Muscidae no lixão urbano de Presidente Prudente, SP.

\section{PROCEDIMENTOS METODOLÓGICOS}

As moscas foram capturadas três vezes em cada estação (inicio, meio e fim), no período de março de 2006 a março de 2009, no lixão urbano, localizado no Distrito Industrial, distante a cerca de seis quilômetros do centro do município de Presidente Prudente - SP, com área aproximada de $90.000 \mathrm{~m}^{2}$ e perímetro de 1,36 km, no espigão divisor e com quantidade significante de vegetação ao seu entorno.

Para a coleta dos insetos foram utilizadas seis armadilhas, confeccionadas com garrafas tipo "pet" (2 litros) semelhantes as utilizado por Ferreira (1978) e modificadas por Seolin Dias et al. (2009), suspensas em arvores, a uma altura de 1,20 a 1,5 m do solo contendo cada aproximadamente $350 \mathrm{~g}$ de fígado bovino.

A cada captura, as garrafas e o atrativo foram substituídos, e os indivíduos coletados transferidos para um frasco de vidro contendo álcool 70\%. Quando necessário, um inseticida aerossol à base de piretróide foi aplicado para matar as moscas vivas no interior das armadilhas.

As moscas foram dispostas em placas de Petri e submetidas à secagem em estufa $50^{\circ} \mathrm{C}$, de 30 a 40 minutos, a depender do número de espécimes capturados, com a finalidade de facilitar a sua visualização, realizada com auxílio de microscópio estereoscópio, e identificação com base na chave dicotômica das espécies (CARVALHO; RIBEIRO, 2000; CARVALHO, MOURA, RIBEIRO, 2002). 


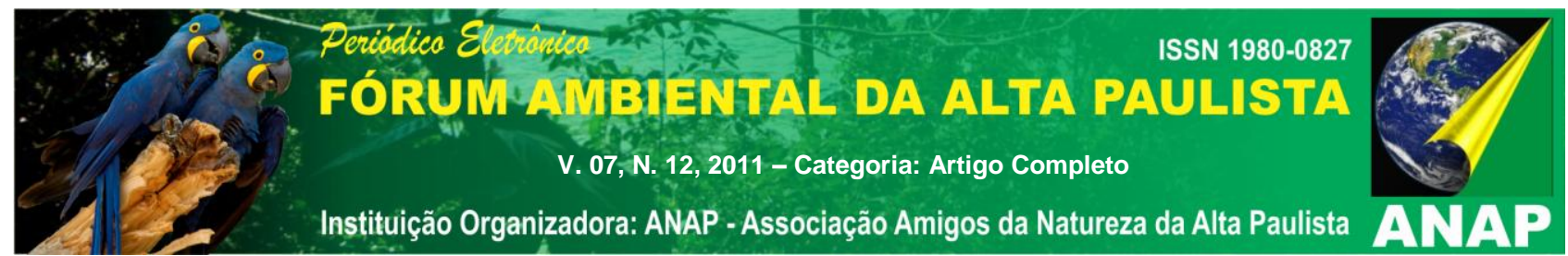

Os registros climáticos foram obtidos na Estação Meteorológica da UNESP, campus Presidente Prudente, vinculada ao Instituto de Pesquisas Meteorológicas (INMET).

Os dados dos elementos climáticos foram tratados por meio de técnicas estatísticas descritivas e Para cálculo da temperatura e umidade médias e índice da precipitação pluviométrica, foram obtidos os dados dos 10 dias que antecederam cada captura, para avaliação das intempéries climáticas sobre as contagens de moscas.

\section{RESULTADOS}

Durante os três anos de monitoramento foram capturados 26.508 indivíduos, sendo 87,48\% (23.189) pertencentes à família Calliphoridae e 12,52\% (3.319) à Muscidae. A frequência das moscas, por estação, pode ser analisada na Tabela 1.

Tabela 1: Número total de dípteros das famílias Calliphoridae e Muscidae capturadas e seus respectivos percentuais, distribuídos nas quatro estações do ano, no período de março de 2006 a março de 2009, no lixão urbano de Presidente Prudente, SP.

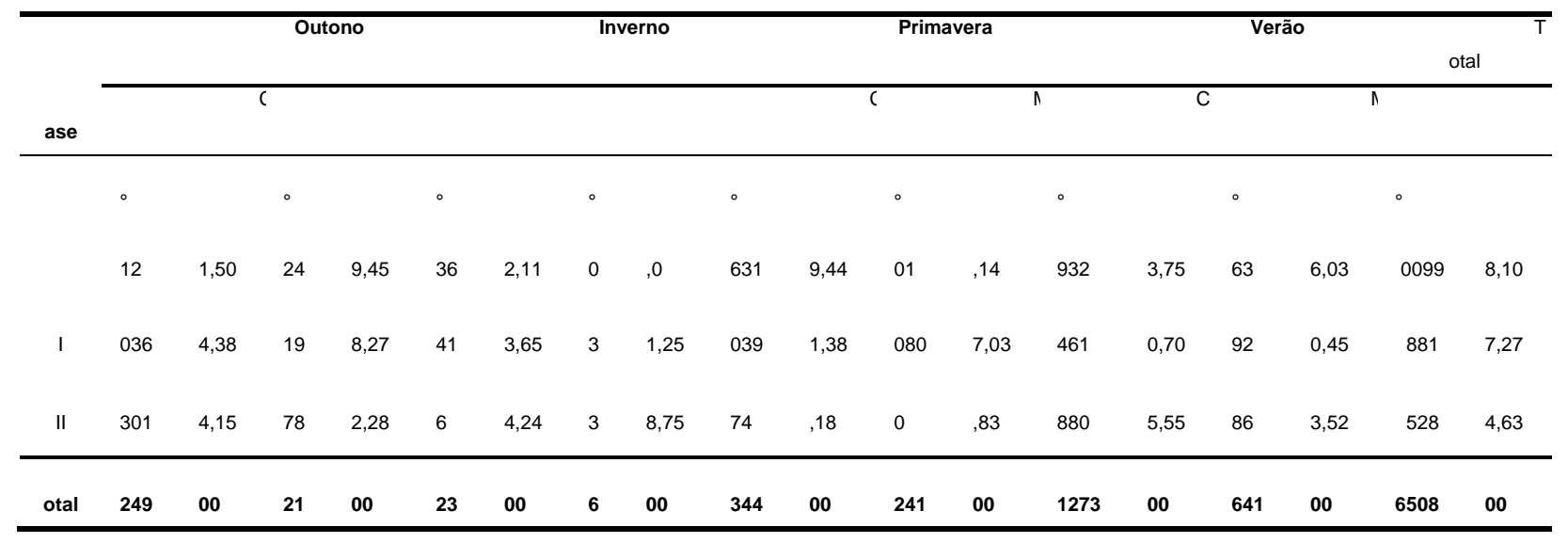

* Fase I (março/2006 a março/2007); Fase II (março/2007 a março/2008) e Fase III (março/2008 a março/2009)

${ }^{*} \mathrm{C}=$ Calliphoridae; $\mathrm{M}=$ Muscidae

De modo geral, as condições climáticas registradas durante o trabalho podem ser consideradas típicas para a região. Durante os três anos de estudo, as temperaturas 


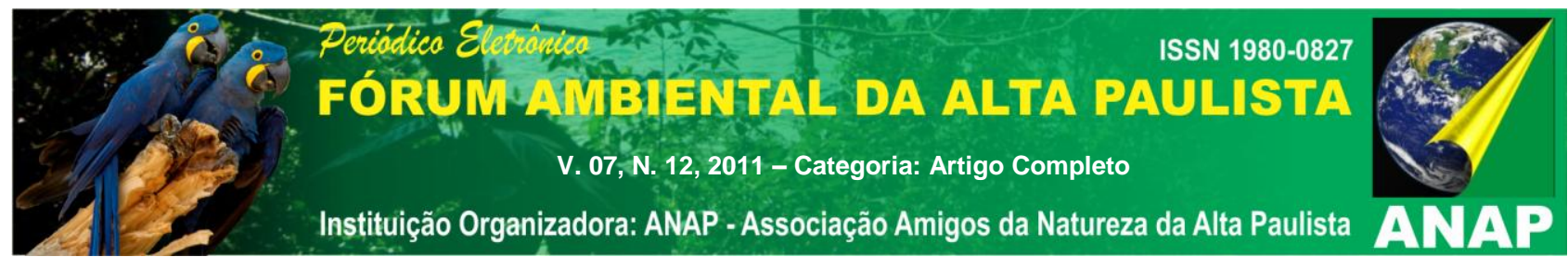

médias mensais oscilaram de 15 . a $32.2^{\circ} \mathrm{C}$ na primeira fase do estudo, 16.4 a $33.5^{\circ} \mathrm{C}$ na segunda e 15.5 a $31.5^{\circ} \mathrm{C}$ na terceira. Mantiveram-se mais elevadas na estação do verão, nas três fases do estudo. Com média de $26.4^{\circ} \mathrm{C}$ na primeira fase, $26.1^{\circ} \mathrm{C}$ na segunda e $26.5^{\circ} \mathrm{C}$ na terceira. Nas primaveras $\left(25.6,26.3\right.$ e $\left.25.7^{\circ} \mathrm{C}\right)$ nas três fases respectivamente. Nas estações de outono $\left(23.2,24.4\right.$ e $\left.23.7^{\circ} \mathrm{C}\right)$ e nas estações de invernos $(22.1,22.0$ e $22.3^{\circ} \mathrm{C}$ ), conforme as três fases do estudo.

A umidade relativa média mensal variou de 29.9 a $92.3 \%$ na primeira fase, 30.7 a 89.0\% na segunda e 33.6 a $90.1 \%$ na terceira. Foram mais altas nas estações de verão e outono, verificou-se no primeiro ano de observação do verão a média de $68.2 \%, 71.5 \%$ no segundo e $73.9 \%$ no terceiro. Nas estações de outono a umidade relativa manteve-se alta com médias de $(69.4,65.7$ e 66.1\%), nos três anos do estudo. Entretanto, este fator abiótico teve médias mais baixas nas estações de primavera (62.7, 56.6 e $63.5 \%)$ e nas estações de inverno (57.7, 54.6 e 53,1\%).

As precipitações anuais em 2006, 2007 e 2008 foram 1.239, 1.248 e 1.444 mm; respectivamente. Além disso, os maiores índices ocorreram nas estações de verão, com $735 \mathrm{~mm}$ na primeira fase, $500 \mathrm{~mm}$ na segunda e $792 \mathrm{~mm}$ na terceira. Nas estações de primavera (339, 266 e 198 mm) e nas estações de outono (92, 230 e 362 mm). Os menores índices de precipitação pluvial ocorreram nas estações de inverno 72 mm, 251 $\mathrm{mm}$ e $91 \mathrm{~mm}$, respectivamente.

Nos três anos de estudo, os califorídeos foram os mais numerosos e mais constantes nas quatro estações, com predomínio nos meses mais quentes e úmidos do ano (verão). Posteriormente, apresentaram maior população nos dois primeiros anos, durante a primavera e, no terceiro ano no outono. A população destes dípteros foi muito reduzida nos meses mais frios e secos (inverno), com 136, 141 e 56 exemplares, respectivamente.

De forma semelhante, os muscídeos tiveram maior frequência no verão, apresentando nos dois primeiros anos segunda maior frequência na primavera e, no terceiro ano no outono. As capturas foram reduzidas ou ausentes no inverno, em 2006, 2007 e 2008, com população de insetos coletadas de 0, 13 e 03 insetos, respectivamente.

A predominância dos membros das duas famílias nos meses quentes com temperaturas superiores a $22.0^{\circ} \mathrm{C}$ e inferiores a $26.1^{\circ} \mathrm{C}$ demonstrou que a temperatura é 


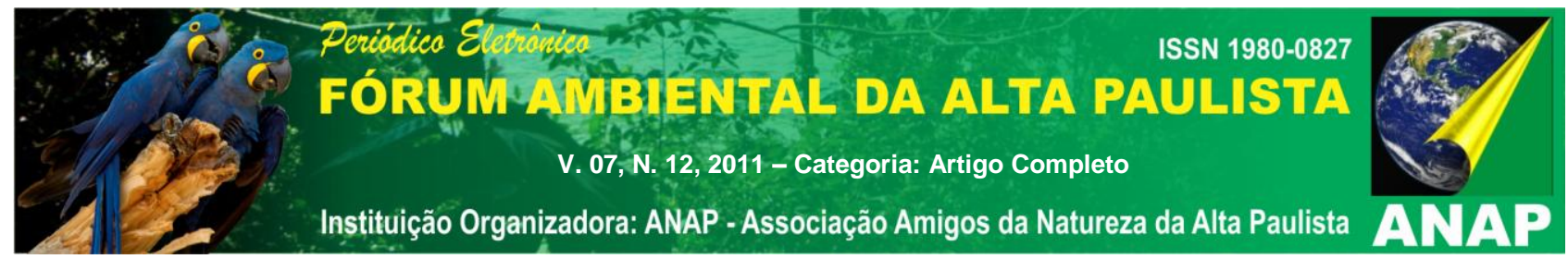

um fator importante na flutuação populacional das famílias estudadas, uma vez que a oferta alimentar no lixão urbano não diminuiu drasticamente.

\section{CONCLUSÕES}

Os membros da família Calliphoridae, nos três anos de estudo, em todas as estações, foram mais família de maior abundância.

A maior incidência de moscas ocorreu na estação do verão dos três anos estudados, devido à característica climática em que predominam altas temperaturas e umidades, que possibilitam condições favoráveis para a proliferação das moscas.

Os resultados apontam para a necessidade de se realizarem outros estudos, com o objetivo de desvendar aspectos comportamentais dos califorídeos e muscídeos relacionados a outros fatores climáticos como: insolação, vento, pressão entre outros.

\section{REFERÊNCIAS}

AMORIM, M. C. C. T. O clima urbano de Presidente Prudente/SP. Tese de Doutorado em Geografia. Universidade de São Paulo, São Paulo, 2000

AMORIM, M. C.C. T. Características do clima urbano de Presidente Prudente/SP. In: Os climas das cidades brasileiras. Presidente Prudente: [s.n.], p.165-196, 2002.

AMORIM, M.C. C. T. et al. Características das ilhas de calor em cidades de porte médio: exemplos de Presidente Prudente (Brasil) e Rennes (França). Revista Confins [Online], 7 | 2009.

ARAÙJO, A. et al. Ensaio metodológico sobre a utilização de transectos móveis no período diurno em Presidente Prudente-SP. Revista Formação, número 17, v.1, de 2010

BOIN, M. R. Chuvas e Erosões no Oeste Paulista: Uma Análise Climatológica Aplicada. Tese de doutorado em Geografia. UNESP Rio Claro, 2000. 264 p.

BOLETIM CLIMATOLÓGICO. Presidente Prudente: Faculdade de Ciências e Tecnologia UNESP, 1999, ano 03, n. 04.Meteorológica (FCT/UNESP) de Presidente Prudente.

CARVALHO, C. J. B.; RIBEIRO, P. B. Chave de identificação das espécies de Calliphoridae (Diptera) do sul do Brasil. Revista Brasileira de Parasitologia, v.9, p.255268, 2000. 


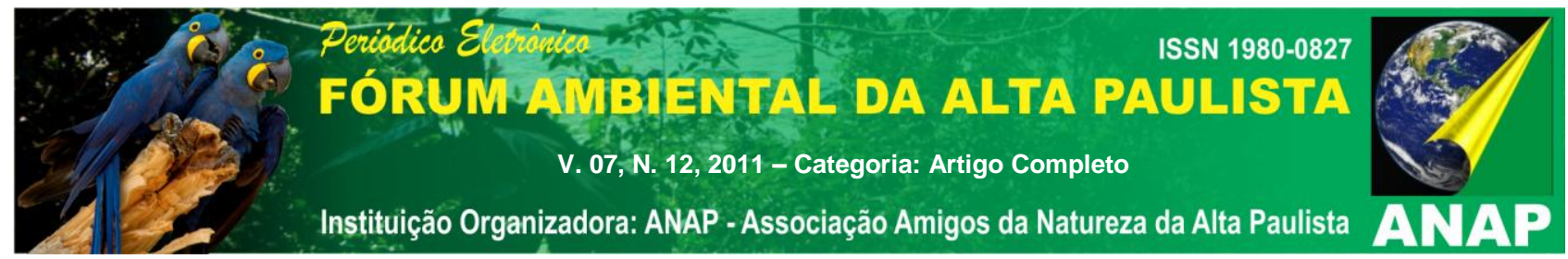

CARVALHO, C. J. B.; MOURA, M. O.; RIBEIRO, P. B. Chave para adultos de dípteros (Muscidae, Fanniidae, Anthomyiidae) associados ao ambiente humano no Brasil. Revista Brasileira de Entomologia, v. 46, n. 2: p. 107-114, 2002.

DAKSHINAMURTI, S. The common house fly, Musca domestica L., and its behavior to temperature and humidity. Bulletin of Entomological Research, v. 39, p. 339-357, 1948.

FERREIRA, M. J. M. Sinantropia de dípteros muscóides de Curitiba, Paraná I. Calliphoridae. Revista Brasileira de Biologia, v. 38, p. 445-454, 1978.

FORATTINI, O. P. Entomologia médica. $1^{\underline{a}}$ ed. São Paulo. Faculdade de higiene e saúde pública - Departamento de Parasitologia. 1962. 661p.

LARA, F. M. Princípios de entomologia. Faculdade de Ciências Agrárias e Veterinárias (Unesp), Jaboticabal, SP, 1977. 278p.

MINKIN, J. S.; SCOTT, H. G. House fly pupation under baseboards. J Econ Ent., v.53, n.3, p.479-480, 1960.

RODRIGUES, W. C. Fatores que influenciam no desenvolvimento dos insetos. Info insetos. Ano 01, n. 4, p. 01-04. Disponível em:

http://www.infoinsetos.ebras.bio.br/pdf/art0104-01.pdf. Acesso em agost. 2011.

SEOLIN DIAS, L.; SANTARÉM, V.A.; ALMEIDA, M.S.R.; MEDINA, A.O.; SILVA, A.V. da. Biodiversidade de moscas Calliphoridae no lixão urbano de Presidente Prudente, São Paulo, Arquivos do Instituto Biológico, São Paulo, v. 76, p.659-663, 2009.

SIVERLY, R. E. Effects of chilling of pupae on subsequent emergence of resistant and susceptible house flies. Ibid, v.51, n.5, p.666-668, 1958.

STEVE, P. C. Parasites and predators of Fannia canicularis (L.) and Fannia scalaris (F.). Ibid, v. 52, p. 530-531, 1959.

THORSTEINSON, A. J. The orientation of horse flies and deer flies (Tabanidae, Diptera). I. The attractance of heat to tabanids. Ent. Expt. Appl., v.1, n.3, p.191-196, 1958.

TORRES, J. R.; OLIVEIRA, C. M. B.; WALD, V. B. Influência sazonal sobre os períodos de pré-pupa e de pupa de Musca domestica, na região de Porto Alegre, RS, Brasil. Acta Scientiae Veterinariae, v. 30, p. 37-42, 2002. 